\title{
Challenges, Solutions, and Workflows Developed for the Taxonomic Backbone of the World Flora Online.
}

\author{
William Ulate ${ }^{\ddagger}$, Sunitha Katabathuni ${ }^{\ddagger}$, Alan Elliott ${ }^{\S}$ \\ ‡ Missouri Botanical Garden, St. Louis, MO, United States of America \\ $\S$ Royal Botanic Garden Edinburgh, Edinburgh, United Kingdom
}

Corresponding author: William Ulate (william.ulate@mobot.org)

Received: 15 Sep 2021 | Published: 16 Sep 2021

Citation: Ulate W, Katabathuni S, Elliott A (2021) Challenges, Solutions, and Workflows Developed for the Taxonomic Backbone of the World Flora Online. Biodiversity Information Science and Standards 5: e75343. https://doi.org/10.3897/biss.5.75343

\begin{abstract}
The World Flora Online (WFO) is the collaborative, international initiative to achieve Target 1 of the Global Strategy for Plant Conservation (GSPC): "An online flora of all known plants." WFO provides an open-access, web-based compendium of the world's plant species, which builds upon existing knowledge and published floras, checklists and revisions but will also require the collection and generation of new information on poorly known groups and unexplored regions (Borsch et al. 2020).
\end{abstract}

The construction of the WFO Taxonomic Backbone is central to the entire WFO as it determines the accessibility of additional content data and at the same time, represents a taxonomic opinion on the circumscription of those taxa. The Plant List v.1.1 (TPL 2013) was the starting point for the backbone, as this was the most comprehensive resource covering all plants available. We have since curated the higher taxonomy of the backbone, based on the following published community-derived classifications: the Angiosperm Phylogeny Group (APG IV 2016), the Pteridophyte Phylogeny Group (PPG I 2016), Bryophytes (Buck et al. 2008), and Hornworts \& Liverworts (Söderström et al. 2016).

The WFO presents a community-supported consensus classification with the aim of being the authoritative global source of information on the world's plant diversity. The backbone is 
actively curated by our Taxonomic Expert Networks (TEN), consisting of specialists of taxonomic groups, ideally at the Family or Order level. There are currently 37 approved TENs, involving more than 280 specialists, working with the WFO. There are small TENs like the Begonia Resource Center and the Meconopsis Group (with five specialists), medium TENs like Ericaceae and Zingiberaceae Resource Centers or SolanaceaSource.org (around 15 experts), and larger TENs like Caryophyllales.org and the Legume Phylogeny Working Group, with more than 80 specialists involved. When we do not have taxonomic oversight, the World Checklist of Vascular Plants (WCVP 2019) has been used to update those families from the TPL 2013 classification. Full credit and acknowledgement given to the original sources is a key requirement of this collaborative project, allowing users to refer to the primary data. For example, an association with the original content is kept through the local identifiers used by the taxonomic content providers as a link to their own resources.

A key requirement for the WFO Taxonomic Backbone is that every name should have a globally unique identifier that is maintained, ideally forever. After considering several options, the WFO Technology Working Group recommended that the WFO Council establish a WFO Identifier (WFO-ID), a 10-digit number with a "wfo-" prefix, aimed at establishing a resolvable identifier for all existing plant names, which will not only be used in the context of WFO but can be universally used to reference plant names.

Management of the WFO Taxonomic Backbone has been a challenge as TPL V1.1 was derived from multiple taxonomic datasets, which led to duplication of records. For that reason, names can be excluded from the public portal by the WFO Taxonomic Working Group or the TENs, but not deleted. A WFO-ID is not deleted nor reused after it has been excluded from the WFO Taxonomic Backbone. Keeping these allows for better matching when assigning WFO-IDs to data derived from content providers. Nevertheless, this implies certain considerations for new names and duplications.

New names are added to the WFO Taxonomic Backbone via nomenclators like the International Plants Name Index (IPNI, The Royal Botanic Gardens, Kew et al. 2021) for Angiosperms, and Tropicos (Missouri Botanical Garden 2021) for Bryophytes, as well as harvesting endemic and infraspecific names from Flora providers when providing descriptive content. New names are passed to the TEN to make a judgement on their taxonomic status.

When TENs provide a new authoritative taxonomic list for their group, we first produce a Name Matching report to ensure no names are missed. Several issues come from managing and maintaining taxonomic lists, but the process of curating an ever-growing integrated resource leads to an increase in the challenges we face with homonyms, nonstandard author abbreviations, orthographic variants and duplicate names when Name Matching.

The eMonocot database application, provided by Royal Botanic Gardens, Kew, (Santarsiero et al. 2013) and subsequently adapted by the Missouri Botanical Garden to 
provide the underlying functionality for WFO's current toolset, has also proven itself to be a challenging component to update.

In this presentation, we will share our hands-on experience, technical solutions and workflows creating and maintaining the WFO Taxonomic Backbone.

\section{Keywords}

WFO, taxonomy, GSPC

\section{Presenting author}

William Ulate

\section{Presented at}

TDWG 2021

\section{References}

- $\quad$ APG IV (2016) An update of the Angiosperm Phylogeny Group classification for the orders and families of flowering plants: APG IV. Botanical Journal of the Linnean Society 181 (1): 1-20. https://doi.org/10.1111/boj.12385

- $\quad$ Borsch T, Berendsohn W, Dalcin E, Delmas M, Demissew S, Elliott A, Fritsch P, Fuchs A, Geltman D, Güner A, Haevermans T, Knapp S, Roux MM, Loizeau P, Miller C, Miller J, Miller J, Palese R, Paton A, Parnell J, Pendry C, Qin H, Sosa V, Sosef M, RaabStraube E, Ranwashe F, Raz L, Salimov R, Smets E, Thiers B, Thomas W, Tulig M, Ulate W, Ung V, Watson M, Jackson PW, Zamora N (2020) World Flora Online: Placing taxonomists at the heart of a definitive and comprehensive global resource on the world's plants. Taxon 69 (6): 1311-1341. https://doi.org/10.1002/tax.12373

- Buck W, Shaw A, Goffinet B (2008) Morphology, anatomy, and classification of the Bryophyta. In: Goffinet B, Shaw A (Eds) Bryophyte Biology. Cambridge University Press

- Missouri Botanical Garden (2021) Tropicos.org. http://www.tropicos.org. Accessed on: 2021-8-02.

- $\quad$ PPG I (2016) A community-derived classification for extant lycophytes and ferns. Journal of Systematics and Evolution 54 (6): 563-603. https://doi.org/10.1111/jse.12229

- Santarsiero A, Clark B, Kelly J, Godfray C (2013) eMonocot: A successful virtual community. https://static.tdwg.org/conferences/2013/presentations/ Santarsiero eMonocot.pdf. Accessed on: 2021-8-02.

- Söderström L, Hagborg A, von Konrat M, Bartholomew-Began S, Bell D, Briscoe L, Brown E, Cargill DC, da Costa DP, Crandall-Stotler B, Cooper E, Dauphin G, Engel J, Feldberg K, Glenny D, Gradstein SR, He X, Hentschel J, Ilkiu-Borges AL, Katagiri T, Konstantinova N, Larraín J, Long D, Nebel M, Pócs T, Puche F, Reiner-Drehwald E, Renner M, Sass-Gyarmati A, Schäfer-Verwimp A, Segarra-Moragues J, Stotler R, 
Sukkharak P, Thiers B, Uribe J, Váňa J, Wigginton M, Zhang L, Zhu R (2016) World checklist of hornworts and liverworts. PhytoKeys 59: 1-828. https://doi.org/10.3897/ phytokeys.59.6261

- The Royal Botanic Gardens, Kew, Harvard University Herbaria Libraries, Australian National Botanic Gardens (2021) International Plant Names Index, IPNI. http:// www.ipni.org. Accessed on: 2021-5-24.

- TPL (2013) The Plant List, version 1.1. http://www.theplantlist.org/. Accessed on: 2021-8-02.

- WCVP (2019) World Checklist of Vascular Plants, version 2.0. http:// wcvp.science.kew.org/. Accessed on: 2019-12-06. 